\title{
OS RECURSOS DA GAMIFICAÇÃO EM CONTEÚDO DIGITAL MEDIADOS PELA EDUCAÇÃO A DISTÂNCIA
}

\author{
GOIÂNIA/GO AGOSTO/2018 \\ Cristiane Gonçalves Correa - SENAI - cristianegc.senai@sistemafieg.org.br
Paulo de Sá Filho - SENAI - paulodesa.senai@sistemafieeg.org.br \\ Tipo: Relato de Experiência Inovadora (EI) \\ Categoria: Métodos e Tecnologias \\ Setor Educacional: EDUCAÇÃO MÉDIA E TECNOLÓGICA
}

\begin{abstract}
RESUMO
Os elementos e conceitos da gamificação aos poucos vêm sendo explorados e inseridos no contexto da educação, apresentando uma proposta de ensino personalizada e adaptativa, baseada na inovação tecnológica, práticas atrativas e motivadoras, que vão ao encontro com os anseios da educação à distância no uso das novas tecnologias de informação e promoção do conhecimento. Este artigo se constitui de um relato acerca da estrutura e dos conceitos de gamificação inseridos em um conteúdo digital desenhado para acesso sem o uso de internet (offline) e utilizado como recurso didático para um curso de qualificação profissional na modalidade EaD do SENAl regional de Goiás. Além disso, a fim de analisar os resultados proporcionados pela aplicação dos conceitos de gamificação utilizados no curso é apresentada uma pesquisa que retrata a percepção e visão dos alunos concluintes no primeiro semestre de 2018. Os resultados evidenciam a satisfação dos alunos em relação aos conceitos de gamificação praticados, que além de reconhecerem a contribuição dos conceitos de games inseridos no curso como parte do processo de capacitação rumo ao mundo do trabalho, proporcionou aos concluintes um novo olhar para o futuro ao lidarem com os desafios, planos, superações e conquistas pessoais e profissionais.
\end{abstract}

Palavras-chave: Educação a Distância, Gamificação, Qualificação. 


\section{Introdução}

É notório que ao longo do tempo o processo de educação vem assumindo novos desafios, se adequando as transformações e anseios da sociedade globalizada. Buscando de um lado atender as necessidades da nova geração de alunos que possuem o desejo de um aprendizado dinâmico com metodologias e práticas atrativas, e de outro lado visa acompanhar as inúmeras mudanças sociais, econômicas, políticas e tecnológicas que envolvem toda sociedade, inserindo assim o aluno em um processo de educação dinâmico e, sobretudo atual.

A partir das modificações do mundo contemporâneo e em resposta aos desafios enfrentados pela educação, a modalidade de educação à distância, se sobressai de forma satisfatória ao estabelecer um elo constante com a inovação, tecnologia e ao proporcionar estratégias que estão em constante evolução, presentes na formação profissional e humana. Historicamente a educação à distância, tem aprimorado e ampliando seu processo de aprendizagem, na inserção de recursos que fazem parte da evolução das novas tecnologias da informação e comunicação, e que corresponda com os anseios dos chamados "nativos digitais". (BISSOLOTTI, et al, 2014).

Ao atribuir novas linguagens digitais associadas às tecnologias da informação e comunicação e diante dos interesses das pessoas por jogos, as estratégias de gamificação tornaram-se uma metodologia que recentemente foram incorporadas ao processo de ensino e aprendizagem da educação à distância, a partir da utilização de elementos dos jogos em contextos educacionais, (TENORIO, et al, 2016).

Apesar do conceito games já ser utilizado pela sociedade há algum tempo, atualmente sua capacidade de oferecer uma iteração lúdica que proporciona diversão, entretenimento e engajamento, vem sendo inserido na educação como instrumento frente à inovação tecnológica. Favorecendo a produção de conteúdos e práticas interativas, aprimorando o conhecimento e agregando valor à educação, (AMÉRICO, et al, 2013).

Portanto, práticas atuais como a gamificação na educação a distância (EaD), em conjunto com a aplicação de conteúdos atuais, metodologias ativas, métodos, técnicas e elementos inovadores, tem atraído cada vez mais alunos imersos na cultura digital e ultrapassado os limites e desafios enfrentados pela educação, em meio as transformações vividas pela sociedade contemporânea. 


\section{Referencial Teórico}

\subsection{Gamificação na Educação}

Para SAVI (2008), o setor de entretenimento vem assumindo uma posição de destaque na cultura contemporânea, uma vez que os jogos de vídeo games e computadores estão cada dia mais presente na vida de jovens, crianças e adultos. Tamanho envolvimento e engajamento na resolução de desafios porporcionados pelo uso de jogos digitais, têm levado pesquisadores ao desenvolvimento de jogos educacionais, proporcionando métodos mais atrativos, dinâmicos e motivacionais incorporados ao processo de ensino e aprendizagem.

A atividade de se incorporar os elementos de design de jogos em contextos de não jogos, como realizado na educação, são chamadas de estratégias de gamificação, (COSTA, et al, 2015). "O termo gamificação compreende a aplicação de elementos de jogos em atividades de não jogos", (FADEL, et al, 2014).

De acordo com TOLOMEI, 2017, a gamificação no processo de ensino e aprendizagem, trás consigo os mecanismos dos jogos como: regras, objetivos e resultados e os elementos dos jogos: pontuações, níveis, ranking, medalhas/conquistas, desafios e missões. Nesse contexto esses mecanismos e elementos levam os estudantes a buscarem e avançarem as etapas do jogo, a fim de conquistarem recompensas, de acordo com a evolução e superação individual apresentada em cada desafio, proporcionando ao indivíduo o sentimento de prazer e satisfação no aprendizado e, sobretudo engajamento.

São diversos os benefícios resultantes do uso de recursos e elementos da gamificação, dentre eles: "efeitos motivadores, facilitador do aprendizado, habilidades cognitivas, aprendizado por descobertas, experiências novas, socialização, coordenação motora, dentre outras," (SAVI, 2008).

Nesse sentido, ao empregar os recursos da gamificação na educação seja na modalidade à distância ou presencial, assume-se diversos pontos positivos pautados sob estratégias inovadoras que vão de encontro às atividades e realidades atuais, uma vez que os jogos se assumem diante da sociedade como uma prática social pertencente ao atual cenário cultural.

\section{Objetivo}


Este artigo descreve o uso dos conceitos de gamificação inseridos em um conteúdo digital utilizado como recurso de forma offline, ou seja, sem necessidade de conexão a internet, para os participantes de um curso de qualificação na modalidade EaD do SENAI em Goiás. Para tanto, apresenta-se uma exposição da estrutura do curso e a apresentação dos resultados de uma pesquisa desenvolvida com os alunos concluintes no primeiro semestre de 2018, com o objetivo de apontar a percepção e visão dos alunos no uso dos conceitos e elementos da gaminificação utilizados ao longo do curso.

\section{Procedimentos metodológicos}

O presente relato se refere à apresentação, desenvolvimento, experiências e avaliação do curso de Qualificação em Assistente Administrativo na modalidade de educação à distância (EaD), pelo Programa de Aprendizagem Industrial do SENAI (Serviço Nacional de Aprendizagem Industrial), que utiliza em sua estratégia e metodologia de ensino e aprendizagem o recurso de gamificação.

A apresentação de toda estrutura, desenvolvimento e experiências acerca do recurso da gamificação utilizados no curso, tem por base uma pesquisa bibliográfica, realizada nas documentações e registros institucionais do SENAI, especificamente no Guia de Exceção do curso elaborado pelo Departamento Nacional e Departamento Regional de Santa Catarina (2015).

Para avaliação e apresentação de resultados, quanto ao uso dos conceitos de gamificação no curso foi realizada uma pesquisa exploratória, de abordagem qualitativa e quantitativa, utilizando de um formulário on line. O cenário de pesquisa foi o curso de Qualificação em Assistente Administrativo na modalidade de educação a distância (EaD), do SENAI, regional de Goiás. Os participantes da pesquisa foram os alunos concluintes do curso no primeiro semestre de 2018 da turma de 2017/01. A pesquisa foi desenvolvida entre os meses de maio e julho do ano de 2018.

\subsection{Apresentação do Curso}

Curso de Qualificação em Assistente Administrativo na modalidade à distância, foi desenvolvido pelo Serviço Nacional de Aprendizagem Industrial, a fim de atender uma demanda de jovens com idade entre 16 a 24 anos. Jovens em situação de vulnerabilidade social, com moradia em diversas localidades geográficas, locais em que o SENAI não possui estrutura física (escola) ou que não possuem quantitativo de estudantes (mínimo de 25 alunos) para abertura de uma turma. 
O curso se baseia na metodologia SENAI de educação profissional, que tem como objetivo de preparar jovens para a vida profissional e mercado de trabalho, traduzindo as informações do "mundo do trabalho para o mundo da educação".

A estrutura do curso, de acordo com programa de aprendizagem industrial, é composto de fase empresa e fase escolar. A fase empresa ocorre de forma presencial na empresa/indústria a qual o aluno é lotado e orientado por um representante da mesma e a fase escolar será ofertada por meio do curso a distância no formato online (para os alunos que possuem acesso a internet) e offline (para os alunos que não possuem acesso à internet), mediado e acompanhado pelo corpo docente do SENAI (professores/tutores a distância e presenciais) e coordenações técnicas e administrativas.

Para realização do curso é disponibilizado aos estudantes os livros didático (impresso ou através do acesso à estante virtual do SENAI), o material didático chamado de conteúdo digital é disponibilizado ao aluno e instalado no computador, possibilitando o acesso tanto para aquele estudante que possui o acesso a internet quanto àquele que não possui acesso a internet, uma vez que esse conteúdo encontra-se embarcado no desktop. Além dos livros didáticos e conteúdo digital o aluno que possui acesso à internet realiza as interações com o professor/tutor através do AVA (Ambiente Virtual de Aprendizagem).

O grande diferencial do curso se dá pelo fato de ser ofertado na modalidade a distância no alcance máximo de jovens em todo país, na redução de custos, dentre outras vantagens da modalidade. Além disso, pela garantia e possibilidade de interação, contato e desenvolvimento com todos os conteúdos, atividades e estrutura, que se apresentam com a mesma qualidade e estrutura, tanto para os estudantes que possuem acesso à internet quanto para os estudantes que não possuem acesso a internet, uma vez que o material didático, ou seja, conteúdo digital disponibilizado e o mesmo para os dois formatos.

O conteúdo digital, ou seja, o material didático do curso foi desenvolvido com base nos conceitos e elementos da gamificação. Que leva os estudantes a vivenciarem a realidade de sua futura profissão, através de uma metáfora que aborda todos os conteúdos, presente nas 11 unidades curriculares da grade do curso. Nessa proposta cada unidade curricular é um desafio onde todas as fases devem ser cumpridas, a fim de garantir o alcance das conquistas, premiações e troféus, gerando motivação, incentivo, despertando a curiosidade e vontade de progredir na conclusão dos conteúdos e atividades. 
A utilização diária do conteúdo digital se dá através do uso de uma senha pessoal de acesso, cadastrada no inicio do curso e que deve ser utilizada até a finalização do curso. Uma senha de acesso padrão é fornecida pelo tutor no inicio de cada unidade curricular, a fim de liberar o acesso inicial nas unidades curriculares, cumprindo o plano e cronograma de aula proposto no inicio do curso e, sobretudo para o melhor acompanhamento de toda turma pelo tutor. Sendo assim, o aluno só consegue progredir para outra unidade curricular de acordo com os comandos do mediador/tutor, delimitando assim algumas das regras presente no jogo.

Ao entrar no conteúdo digital os estudantes terão acesso à tela inicial, que funciona como um mapa direcionador de todo conteúdo presente em cada unidade curricular. A estrutura da tela inicial é compreendida por botões (home, desafio, suas conquistas, ajuda) e figuras clicáveis (recordações, guia do aprendiz, equipe técnica, mapa de navegação, empresa e você na empresa), que trazem informações e orientações iniciais para o estudo e navegação ao longo de todo conteúdo digital.

Dentre os botões presentes na tela inicial, o botão desafio será um dos mais utilizados pelo aluno, uma vez que o acesso ao mesmo possibilita ao aluno o contato há diversas etapas, com atividades a serem cumpridas e superações a serem realizadas, as quais serão acompanhadas pelo professor/tutor de acordo com a evolução do estudante por meio de relatórios de sua progressão (botão "suas conquistas") individual de cada aluno. Assim que o aluno clica no botão "desafio" ele passa a ter acesso aos elementos do conteúdo digital presente em todas as unidades curriculares, composto pelo ponto de partida, que trás um vídeo com a contextualização do desafio e as fases do desafio.

O desafio e composto por fases representadas pelos ícones: Leitura, História em quadrinho, Praticando, Pensando nisso, Vídeo Aula e Superação, que inicialmente são bloqueados e conforme progressões dos alunos, as fases e ícones vão sendo liberadas automaticamente fazendo com que os alunos acumulem e sejam premiados com estrelas, taças, troféus e coroas, até o alcance da linha de chegada garantindo assim seu bônus ao finalizar todo desafio.

A seguir de acordo com SENAI (2015), serão apresentadas na tabela algumas das figuras clicáveis presentes na tela home e alguns exemplos dos ícones utilizados na tela do desafio, que abordam os conceitos e elementos de gamificação, abordados no decorrer do curso.

Tabela 01 _ ícones de Aprendizagem do Conteúdo Digital 


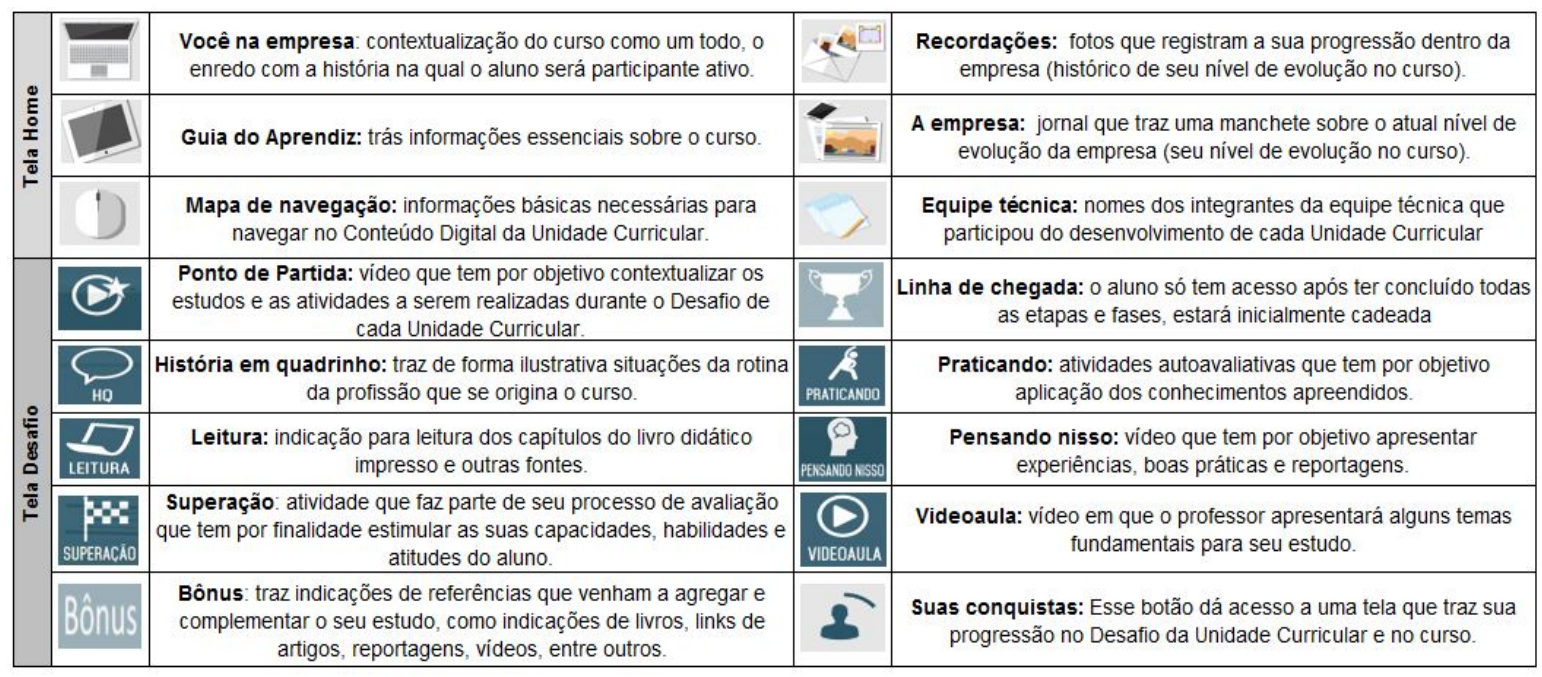

Fonte: Adaptado pelo autor, SENAI (2015)

Ao finalizar o desafio, os alunos devem encaminhar ao professor/tutor o relatório com resultado de suas conquistas, gerado em formato de PDF através do botão suas conquistas presente na tela do desafio, que mostra o resultado em percentual da progressão e desempenho do aluno. Além de demonstrar o percentual geral acumulado pelo aluno ao cumprir o desafio da unidade curricular, o relatório possibilita a visualização da quantidade de estrelas, taças, troféus e coroas, que incentivam e geram motivação no desenvolvimento do curso.

Diante desse contexto, todos os princípios básicos da gamificação utilizados no curso, através do "conteúdo digital", fazem com que os alunos sintam-se motivados e inseridos no contexto de sua profissão e formação. Utilizando-se dos conceitos e técnicas presentes nos games sob uma linguagem que se adéqua a idade e oportuniza maior envolvimento e aprendizado por parte do aluno.

\section{Apresentação e discussão dos resultados}

Conforme metodologia apresentada foi aplicado enviado aos 23 alunos concluintes do curso no primeiro semestre de 2018 um convite para participação da pesquisa através de um questionário online. Obtendo retorno de 22 alunos, que formaram a amostra dessa pesquisa, possibilitando a análise dos resultados proporcionados pela aplicação dos conceitos de gamificação, no que se refere à satisfação dos alunos no uso do recurso de gamificação no curso de qualificação em assistente administrativo na modalidade à distância ofertado pelo SENAI, regional de Goiás.

A primeira parte da pesquisa centralizou na identificação do perfil dos estudantes. No inicio do curso $60,9 \%$ dos alunos tinham idade entre 16 a 18 anos e $39,1 \%$ mais de 18 
anos de idade, dados que apresentam uma faixa etária de jovens que facilita muito o entendimento e aceitação das linguagens dos games no curso. Em relação à formação $47,8 \%$ já estavam cursando uma faculdade em concomitante com o curso de qualificação e $34,8 \%$ com segundo com grau completo, somente uma parcela bem pequena de $17,4 \%$ ainda se encontrava realizando o segundo grau. Outra pergunta que identifica o perfil foi notoriamente a presença de $60,9 \%$ de alunos do sexo feminino e $39,1 \%$ do sexo masculino. De acordo com análises acerca do perfil dos alunos, pode-se identificar um público jovem e que se adapta facilmente com os recursos gamificados.

$\mathrm{Na}$ segunda parte do questionário, as perguntas foram direcionadas especificamente para visualizar e evidenciar a satisfação dos alunos no uso dos conceitos de gamificação. Dentre essas perguntas, três delas apontaram um percentual de $100 \%$ indicando que o uso do material gamificado foi importante para conclusão do curso, que o fato do material trazer conceitos de gamificação motivou a vontade de aprender no decorrer do curso, além disso retrataram que a linguagem gamificada faz parte do seu dia a dia. Sendo assim, o fato do aluno vivenciar algo que faz parte de seu contexto de vida indubitavelmente favoreceu seu sentimento de satisfação na prática dos conceitos de gamificação, portanto, favoreceu o desenvolvimento, aprendizado e conclusão do curso.

Gráfico 01 _ Fatores de satisfação no uso dos conceitos de gamificação

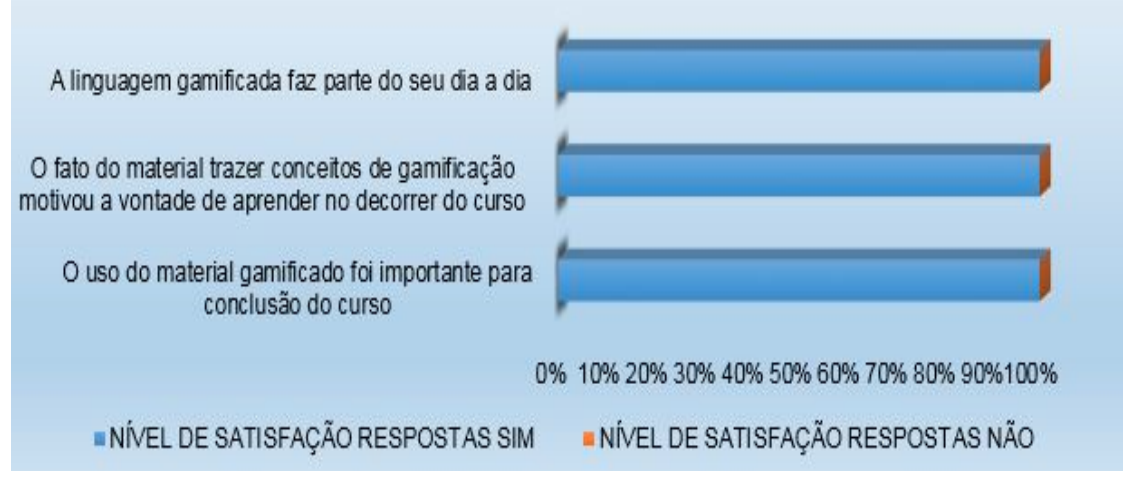

Fonte: Autor

Além das perguntas de múltipla escolha, foi direcionada uma pergunta aberta, onde só reafirmou a aprovação e satisfação do curso no formato gamificado. Conceitos e elementos que influenciaram a maneira de visualizar o futuro em situações de decisões, superações, conquistas e planos pessoais ou profissionais, conforme apontamentos e opiniões por parte de alguns alunos. Seguem citações de alguns registros: 
barreiras. me sinto mas comunicativa. apesar do apoio que eu tive muito da minha tutora. que me ajudava bastante nas minhas dificuldades. esse processo foi importantíssimo parar a minha educação escolar e educação da vida mesmo. eu agradeço muito por ser uma das escolhidas."

"Creio que a forma que foi estudada me qualificou muito."

"Me senti mais preparada para encarar desafios do dia a dia sem medo de errar meio que me trouxe mais motivação e curiosidade de aprender cada dia mais."

\section{Considerações Finais}

Novas formas de pensar a educação e o processo de ensino e aprendizagem por parte da sociedade acadêmica e as constantes exigências e competição acirrada do mundo globalizado, vem quebrando paradigmas e mudanças de posturas da educação tradicional. Em resposta há esse novo olhar a gamificação, ou seja, a linguagem de games surge como um recurso metodológico explorado de forma criativa em conjunto com as novas tecnologias da informação e comunicação na figura da modalidade à distância $(\mathrm{EaD})$.

Ao associar as práticas e metodologias na modalidade de educação distância (EaD), junto as estratégias da linguagem dos jogos, faz com que seja fortalecido um cenário motivador e desafiador capaz de engajar os estudantes rumo as conquistas e superações constantes, seja no ambiente educacional, profissional ou social.

Nesse contexto, a partir do desenvolvimento, execução, prática e resultados satisfatórios de um curso ofertado na modalidade à distância e estruturado com o recurso da gamificação, através de um material didático nomeado por conteúdo digital. O SENAI reafirma seu papel no que tange a formação para indústria de profissionais com capacidades e habilidades sociais, tecnológicas e interativas, exigidas pelo mercado contemporâneo.

A satisfação e aprovação quanto ao uso do recurso da gamificação, ou seja, da linguagem dos jogos presentes no curso ficaram evidenciados nos resultados da pesquisa apresentada sob a visão dos alunos que vivenciaram na prática de forma satisfatória os conceitos de gamificação no decorrer do curso. Conceitos que somaram para uma nova visão de futuro, ao torna-lós pessoas cada vez mais dinâmicas e analíticas, com vontade de vencer todas as fases da vida pessoal e profissional conquistando cada dia seu espaço no mercado de trabalho e, sobretudo na vida.

\section{Referencial Teórico}


AMÉRICO, Marcos; NAVARI, S.C. Gamificação: abordagem e construção conceitual para aplicativo sem TV Digital Interativa. Revista GEMINIS, [S.I.], v. 4, n. 3, p. 87-105, dez. 2013. ISSN 2179-1465. Disponível em: $<$ http://www.revistageminis.ufscar.br/index.php/geminis/article/view/163/132>. Acesso em: 18 jun. 2018.

BISSOLOTTI, K.; NOQUEIRA, H.G.; PEREIRA, A.T.C. Potencialidades das mídias sociais e da gamificação na educação a distância. CIBTEC: Novas Tecnologias na Educação, v.12, n. 2, dez. 2014. Disponível em: <http://seer.ufrgs.br/index.php/renote/article/view/53511>, Acesso em: 18 jun. 2018.

COSTA, Amanda Cristina Santos; MARCHIORI, Patrícia Zeni. Gamificação, elementos de jogos e estratégia: uma matriz de referência. InCID: Revista de Ciência da Informação e Documentação, Ribeirão Preto, v. 6, n. 2, p. 44-65, oct. 2015. ISSN 2178-2075. Disponível em: <http://www.revistas.usp.br/incid/article/view/89912>. Acesso em 20 jun 2018.

FADEL, L.M.; ULBRICHT, V.R.; BATISTA, C.R.; VANZIN,T. Gamificação na educação. São Paulo: Pimenta Cultural, 2014. 300p.

SAVI, R.; ULBRICHT, V. R. Jogos Digitais Educacionais: Benefícios e Desafios. RENOTE - Revista Novas Tecnologias na Educação, v. 6, p. 1-10, 2008.

SENAI. Departamento Nacional. Guia de execução / Serviço Nacional de Aprendizagem Industrial. Departamento Nacional, Serviço Nacional de Aprendizagem Industrial. Departamento Regional de Santa Catarina. Brasília: SENAI/DN, 2015.

TOLOMEI, Bianca Vargas. A Gamificação como Estratégia de Engajamento e Motivação na Educação. EAD EM FOCO, [S.I.], v. 7, n. 2, set. 2017. ISSN 2177-8310. Disponível em: $<$ http://eademfoco.cecierj.edu.br/index.php/Revista/article/view/440>. Acesso em: 28 jun. 2018. 